\title{
PLURIATIVIDADE E AGROINDÚSTRIAS RURAIS NO MARANHÃO: UMA ANÁLISE BASEADA NO CENSO AGROPECUÁRIO DE 2006
}

\section{PLURIACTIVITY AND RURAL AGROINDUSTRIES IN MARANHÃO: AN ANALYSIS BASED ON THE 2006 AGRICULTURAL CENSUS}

\author{
Olena V. Kovtun*
}

\section{Introdução}

Os dados do Censo Agropecuário de 2006, divulgados no ano de 2009, propiciam uma visão mais ampla do que as versões anteriores sobre o retrato do campo agropecuário brasileiro, e já serviram de base para vários debates e discussões sobre os diversos temas na área de agricultura familiar, incluindo também a temática de pluriatividade (SCHNEIDER, FERREIRA, ALVES, 2014). Segundo o Instituto Brasileiro de Geografia e Estatística (IBGE, 2009), o Censo foi elaborado conforme as recomendações e os conceitos básicos consagrados pela Organização das Nações Unidas para a Agricultura e Alimentação (FA0), com vistas a atender aos principais requisitos do Programa del censo agropecuario mundial 2010.
Ao contrário dos documentos anteriores, o Censo de 2006 apresenta as estatísticas que permitem fazer uma análise de produção agrícola familiar de modo comparativo com a produção agropecuária não familiar, assim como apresenta novos aspectos metodológicos sobre a pluriatividade econômica de produtores e dos membros das suas famílias. Com isso, abriu-se a possibilidade de analisar e discutir os resultados relativos à participação da agricultura familiar e não familiar no processamento e beneficiamento agroindustrial realizados nos estabelecimentos dos agricultores, segundo Grandes Regiões e Unidades de Federação (WAQUIL, et al., 2014).

Com base nos questionários aplicados pelos recenseadores, foi definido como estabelecimento pluriativo aquele em que "o

\footnotetext{
* Doutora (Ph.D.) em Ciências Agrárias pela Academia Nacional de Ciências Agrárias da Ucrânia (Kiev/ Ucrânia). Email: okovtun@outlook.com
} 
produtor e/ou algum membro da família exerceu a atividade agropecuária e algum tipo de atividade não agropecuária remunerada e/ou qualquer tipo de atividade remunerada fora do estabelecimento" (SCHNEIDER et al., 2014, p. 111).

De acordo com os resultados divulgados no Censo de 2006 (IBGE, 2009), no estado do Maranhão, entre as atividades não agrícolas mais declaradas pelos agricultores residentes no meio rural, destaca-se a ocupação em agroindústria de produtos ou indústria de transformação, depois das atividades principais da agricultura e pecuária. No estado, encontram-se situadas 262 mil unidades de agricultura familiar, cujas atividades respondem pela produção de entre $65 \%$ a 75 $\%$ das principais culturas alimentares, como milho, feijão, arroz e mandioca e em 41,6 $\%$ pela produção de bovinos no subsetor de pecuária (SEDES, 2014). Entendendo que estes produtos e seus derivados constituem a base de alimentação da maior parte da população maranhense, procurou-se analisar as agroindústrias de alguns desses produtos que tiveram a maior expressão no Censo Agropecuário de 2006 em relação de número de estabelecimentos, a quantidade produzida de matéria prima do próprio estabelecimento e a quantidade destinada à venda.

Face à atualidade e importância da questão de agroindústrias rurais, principalmente de pequeno porte e familiares, e às pesquisas realizadas e divulgadas (SCHNEIDER et al., 2014) em nível nacional sobre o perfil produtivo dos estabelecimentos agroindustriais e a participação de pequenos agricultores (agricultura familiar) na agregação de valor aos produtos agropecuários produzidos nos estabelecimentos familiares ou de terceiros, considerou-se pertinente a realização da pesquisa semelhante com análise da situação das agroindústrias familiares em nível do estado do Maranhão e, de seguida, comparando os dados com os dados de outros estados na região do Nordeste e com os dados de pesquisa em todo Brasil.

0 artigo é organizado da seguinte forma: esta breve introdução, seguida de três partes; considerações finais; e referências bibliográficas. Na primeira parte, será apresentada a reflexão teórica, elaborada por meio de análise das fontes bibliográficas, sobre a importância de diversificação de atividades para o melhoramento das condições econômicas e de vida das famílias rurais, com foco na região Nordeste e no Estado do Maranhão. Na segunda parte, serão apresentados alguns aspetos metodológicos sobre o conceito, tipologia e classificação de agroindústrias rurais, elaborados a partir dos documentos oficiais. A terceira parte tratará da análise de pluriatividade e das agroindústrias rurais do estado, identificadas no Censo Agropecuário de 2006 como atividades pluriativas. No final, serão apresentadas as considerações finais, seguidas de referências bibliográficas.

\section{Pluriatividade, agroindústria familiar e a erradicação de pobreza rural}

Pluriatividade é um termo que teve a sua origem na Europa Ocidental (FRANKLIN, 1969; FULLER, 1990). Mas, os estudos relacionados com o trabalho acessório e as estratégias de reprodução social da pequena empresa agrícola familiar já existiam antes na literatura científica alemã (KAUTSKY, [1903] 2015) e da Rússia (CHAYANOV, 1966). Kautsky (2015) questionava a situação miserável das pequenas propriedades camponesas alemãs, cujos proprietários viam-se obrigados a recorrer a um trabalho acessório para conseguir sobreviver. 
Por el censo de 1895, vemos que del total de agricultores independientes, 502 000, o sea, el 20\%, tienen un oficio auxiliar; 717000 explotaciones agrícolas son de asalariados rurales; 791000 pertenecen a asalariados industriales; y 704000 industriales independientes, la mayoría de ellos artesanos. De 5600000 propietarios agrícolas, solo 2000 000, o sea el 37\% son agricultores independientes sin otro empleo accesorio. Entre 3236000 propietarios de menos de 2 hectáres, se cuentan 417 000, o sea 13\%, 147000 de estas pequeñas explotaciones pertenecen a agricultores independientes con oficio auxiliar; 690000 a obreros agrícolas; 743000 a obreros industriales; y 534000 a artesanos. Es enorme, pues, el número de estas miseras explotaciones híbridas (KAUTSKY, 2015, p. 124).

Ao contrário das grandes empresas agrícolas, cujo objetivo visa unicamente à maximização de lucros, para as pequenas unidades familiares são dois os objetivos mais importantes: i) obter uma renda razoável e ii) garantir que a unidade produtiva possa se reproduzir ao longo do tempo, garantindo, deste modo, os seus rendimentos a longo prazo. E para garantir um equilíbrio entre esses dois objetivos, as famílias criam diversas estratégias de diferenciação das suas unidades produtivas (KAUTSKY, 2015; CHAYANOV, 1966), movidas pela lógica social, força motriz na agricultura, especialmente, na qual domina a produção familiar, pois ela expressa as forças não econômicas que influenciam o desenvolvimento agrícola (PLOEG, VENTURA, MELONE, 2016, p. 21).

$\mathrm{Na}$ atualidade, a pluriatividade tornouse um fenômeno generalizado em regiões ocidentais da União Europeia (UE). Entre diversas estratégias, destinadas ao melhoramento da produção de qualquer empresa agrícola, familiar ou não familiar, Ploeg, Ventura e Milone (2016) incluem também a pluriatividade. Em $80 \%$ das empresas de produção de leite neerlandesas, um dos membros da família possui um trabalho adicional em outro lugar e os rendimentos obtidos desta forma compõem $35 \%$ da renda familiar. As atividades pluriativas ocorrem por meio de combinação de trabalho rural e urbano. Isso acontece, principalmente, entre as famílias jovens recémformadas, que, assumindo o trabalho na unidade agrícola familiar, frequentemente utilizam esta estratégia, de modo a ganhar os rendimentos maiores para reinvestir na própria unidade. Por outro lado, as mulheres, cujos filhos já cresceram, decidem retornar aos seus empregos antigos na cidade. Os autores pontuam que a pluriatividade também pode ser uma maneira de escapar da solidão, embora, na maioria dos casos, a procura de outra ocupação é relacionada com a necessidade de completar os baixos rendimentos, provenientes das atividades unicamente agrícolas. De acordo com os estudos, a pluriatividade é uma característica estrutural que prevalece nas empresas onde os proprietários estão na faixa etária de 35 a 55 anos. Nestes casos, o índice de trabalho pluriativo constitui acerca de 50\% nas famílias, onde homens e mulheres estão diretamente envolvidos na agricultura e têm outro emprego em outro lugar. Mas, embora a pluriatividade seja encontrada em todos os grupos de tamanho da empresa, os estudos revelam que o seu índice diminui nos grandes estabelecimentos.

$\mathrm{Na}$ Itália, o estudo aponta que a tendência de ocupações pluriativas cresceu nos últimos anos, sendo que os grandes agricultores se tornaram, através dos seus empregos pluriativos, uma parte indispensável da infraestrutura agrícola. Segundo este es- 
tudo, $25 \%$ dos homens e mulheres (produtores) em todos os estabelecimentos e, independentemente do tamanho da empresa, são pluriativos. Mas, para outros membros da família, que também trabalham no estabelecimento, este índice aumenta para os 40\%. Nos estabelecimentos com o tamanho mais de 50 ha, a pluriatividade geralmente implica o trabalho nas empresas não agrícolas, principalmente, nos setores industrial ou de serviços. Em geral, a pluriatividade contribui com cerca de 18 bilhões de euros para a agricultura italiana, o que equivale a $65 \%$ do valor bruto de produção (VBP) total da agricultura do país. Deste modo, a pluriatividade é considerada uma das estratégias presentes na agricultura contemporânea da Europa Ocidental, que efetivamente participa na formação do modelo socioeconômico desses países (PLOEG, VENTURA, MILONE, 2016).

No Brasil, a problemática de pluriatividade começou a ser discutida na literatura científica no início da década de 1990, por autores como Anjos (1995); Schneider (1999; 2003; 2003a); Carneiro (1998); Graziano da Silva (1999); Carneiro \&t Maluf (2003); Souza, Lima e Silva (2011), e outros. Atualmente, as questões relacionadas com as novas formas de diversificação de produção agrícola e não agrícola nas comunidades rurais brasileiras estão sendo discutidas, cada vez com maior interesse no contexto multidisciplinar (ANJOS \& CALDAS, 2012; SCHNEIDER, FERREIRA, ALVES, 2014; SILVA, 2015).

As pesquisas realizadas por Souza, Lima e Silva (2011) reforçam a importância de diversificação das atividades e rendas para a melhoria do bem-estar da população rural no Nordeste, tendo em consideração que a baixa ou nenhuma renda proveniente de atividades agrícolas leva as famílias a pro- curarem outras alternativas de sustento, e uma delas é a diversificação de atividades econômicas. Esse fenômeno se revela mais evidente nas regiões do Norte e Nordeste do Brasil. Na análise de pobreza entre as famílias pluriativas e monoativas do meio rural na região Nordeste correspondente ao período de 2003-2009, foi observado por estes autores o aumento de pobreza nas famílias monoativas (só atividades agrícolas) e a diminuição da pobreza dentre as famílias pluriativas (atividades agrícolas e não agrícolas). Os autores referem, ainda, que entre as famílias mais pobres, a diminuição de índice de pobreza foi mais relevante, o que vem confirmar ainda mais a importância de diversificação de atividades. 0 que é mais significante no estudo desses autores é o fato que os índices de pobreza nas famílias não agrícolas e pluriativas são menores, se comparados com as famílias que praticavam só atividades agrícolas.

No Estado do Maranhão, embora alguns dos estudos apontam para o crescimento das atividades não agrícolas em quase todos os ramos de atividades (LIMA, 2008), ainda se registram os maiores valores de índice hiato de pobreza (15,08\%) e índice de severidade de pobreza (10,80\%) comparados com os outros estados do Nordeste, tendo em consideração que esses índices são significativos no estudo de pobreza (SOUZA, LIMA, SILVA, 2011).

Nascimento (2009) defende a opinião diferente. Suas pesquisas pesquisas revelaram que a diversificação de atividades, além de ser um sinal claro de processo de proletarização das pequenas unidades agrícolas nordestinas, não está ajudando a evitar o empobrecimento dessas famílias, que vivem em uma situação de pobreza que as induz a diversificar suas atividades. Mesmo que as possibilidades de diversificação 
existam, elas aparecem em economias locais, mais próximas, ou em redes urbanas, que também, na maioria, são muito precárias, "de modo que não justifica a substituição de uma atividade (agrícola) por outra (não agrícola), uma vez que ambas são precárias" (2009, p.335).

Pode-se concordar com o autor. No caso, os agricultores querem abandonar as suas atividades agrícolas e se inserir em ocupações não agrícolas, em busca de rendimentos maiores e mais estáveis. Neste sentido, observando o caso do Maranhão, onde a precariedade do trabalho não agrícola revela-se pelo fato de que a oferta de trabalho nas grandes empresas de agroindústria e de indústrias transformadoras é assegurada, em primeiro lugar, pela demanda por commodities agrícolas no mercado do comércio mundial e, em segundo, pela condição cíclica ou sazonal destes empregos tendo em conta que, " uma das caraterísticas do agronegócio maranhense é a geração de um número relativamente pequeno de empregos permanentes e de um grande número de assalariados temporários, como, carvoeiros, catadores de raizes, trabalhadores de juquira, etc." (CARNEIRO, 2013, p. 24). Deste ponto de vista, o autor tem razão: não vale a pena abandonar uma atividade agrícola de baixa renda para mudar para outra, não agrícola, que também é precária.

No entanto, na literatura se defende que, a desagrarização no meio rural não significa, necessariamente, o abandono compulsório das atividades por parte dos setores agropecuários mais vulneráveis, como as explorações familiares médias ou muito pequenas. A questão crucial assenta na "diversifıcação de suas fontes de ingresso e na estimulação de busca pela agregação de valor aos produtos no seio do próprio estabelecimento, bem como na exploração de novas linhas de atuação, com ênfase nos chamados nichos de mercado de artigos diferenciados e produtos especiais" (ANJOS \& CALDAS, 2012, p. 13).

Diversos estudos dos autores nacionais (PREZOTTO, 2002; MIOR, 2005; WAQUIL et al., 2014; SILVA, 2015) indicam que, no contexto de pluriatividade, a diversificação das atividades pode ocorrer por meio de criação de agroindústrias familiares, de pequeno porte e artesanais, sendo que estas são apontadas como alternativas econômicas para que a agricultura familiar possa "permanecer e desenvolver-se em paralelo com as agroindústrias de grande escala e assim, poder contribuir para a construção de um novo modelo de desenvolvimento sustentável dentro do qual o rural seja pensado como um todo e não mais apenas ligado à produção agrícola" (PREZOTTO, 2002, p. 135). Prezotto (2010) considera ainda que a organização de agroindústrias nos locais onde estão instaladas as unidades de produção familiares também pode ser vista como alternativa para que os agricultores familiares permaneçam no meio rural.

A diversidade de formas de ocupação em face dos fatores internos à unidade familiar, como a idade, número de membros de família, escolaridade, disponibilidade de terras e outros, segundo Schneider et.al. (2014, p. 113), pode ser dividida em duas tipologias de pluriatividade: intersetorial e agrária. A primeira decorre do crescente processo de articulação e encadeamento de agricultura com outros setores de economia, como indústria, comércio e serviços, “ expressão rural das transformações estruturais mais amplas no mercado de trabalho no período dito pós-fordista, ligada à descentralização e realocalização industrial, à segmentação do mercado de trabalho e à 
flexibilização de relações de trabalho (subcontratação, precarização, informalização) ".

No estado do Maranhão, entre os setores que nos últimos anos se destacaram pela oferta de trabalho pluriativo intersetorial, estão: agropecuária de grande porte, indústria de transformação e beneficiamento açucareira, construção civil e serviços (IMESC, 2015). Em alguns municípios, as atividades ligadas à produção de etanol contribuíram expressivamente para a geração de empregos formais. 0 cultivo de cana-de-açúcar contribuiu para ampliação de mercado do trabalho pluriativo no setor agropecuário e da indústria de transformação de produtos, em especial em atividades de fabricação e refino de açúcar e fabricação de biocombustiveis.

À pluriatividade agrária, nela inclui-se a pluriatividade para-agrícola, que se refere às atividades:

Operações, tarefas e procedimentos que implicam na transformação, beneficiamento e/ou processamento de produção agrícola (in natura ou de derivados) obtida dentro do próprio estabelecimento ou adquirida em parte ou na totalidade de fora e destinada à comercialização. As atividades para-agrícolas podem ter a finalidade de transformar a produção visando o consumo pelos próprios membros de família ou destiná-la à venda (SCHNEIDER et.al. 2014, p. 113).

De acordo com os autores, as agroindústrias rurais familiares apresentam uma forma de pluriatividade para-agrícola, pois se constituem em uma grande diversidade de formas e tamanhos de organização e modelos de gestão, como individuais, associações, condomínios, cooperativas (PREZOTTO, 2010; SCHNEIDER et al., 2014; WAQUIL et al., 2014).
Como exemplo desse tipo de pluriatividade no Maranhão, pode ser destacada a produção de artesanato à base de fibra de buriti, cerâmica, couro, panaria, calçado, ou as atividades não agrícolas relacionadas com a produção artesanal de alimentos, como, por exemplo, os produtos à base de culturas vegetais, como fruto de juçara, cajú e de mandioca ou, animais, carne, leite ou couro. A utilização de meios de produção existentes possibilita a heterogeneidade de oferta de artigos de artesanato, desde peças de vestuário e acessórios da moda, a utensílios para o lar, bem como os produtos alimentares de produção artesanal, como leite, queijo e mel.

Sendo assim, ao contrário de trabalho pluriativo assalariado na indústria de transformação de produtos e no setor agropecuário não familiar, as ocupações em atividades agroindustriais familiares e de pequeno porte surgem dentro da própria unidade da família e empregam os fatores de produção e matérias primas já existentes. Na produção industrial ou artesanal de alimentos, derivados de produtos de origem animal, como carne ou leite, ou vegetal, como mandioca, arroz ou frutas, os produtores utilizam os insumos de produção própria, de agropecuária ou do extrativismo mantendo, deste modo, o vínculo com a produção agrícola. Para Waquil et al. (2014, p. 205, 209), "esta forma de processamento vai permitir aos agricultores obter maiores valores agregados devido ao controle de todas as etapas da cadeia produtiva, como, a produção de matérias primas, fabricação de alimentos, administração das unidades e comercialização direta”, além de possuírem maior autonomia frente aos mercados. 


\section{Os aspectos metodológicos sobre o conceito e a classificação das agroindústrias}

Segundo a definição apresentada pelo Instituto Brasileiro de Geografia e Estatística, entende-se como agroindústria rural:

As atividades de transformação e beneficiamento de produtos agropecuários de origem animal ou vegetal, realizadas em instalações próprias comunitárias ou de terceiros, a partir de matéria-prima produzida no próprio estabelecimento agropecuário ou adquirida de outros produtores, desde que a destinação final do produto tivesse sido dada pelo produtor (IBGE, 2009, p.62).

0 Programa de Agroindustrialização de Agricultura Familiar 2007-2010, coordenado pela Secretaria de Agricultura Familiar do MDA, estabeleceu um conceito mais amplo de agroindústria, seguindo a ótica do desenvolvimento microrregional, entendendo:

Agroindustrialização como o beneficiamento e transformação de produtos provenientes de explorações aquícolas, pecuárias, pesqueiras, agrícolas, extrativista e florestais, abrangendo desde processos simples, como classificação e embalagem, até mais complexos, como extração de óleos e a fermentação, incluindo também o artesanato no meio rural (SILVA, 2012, p.4).

Esta defınição, ao contrário da primeira, permite situar melhor a participação dos pequenos agricultores nos processos mais simples de processamento de produtos agropecuários destinados à venda. 0 Programa foi criado para apoiar a inclusão dos agricultores familiares no processo de agroindustrialização e comercialização, vi- sando a agregar o valor aos produtos, gerar renda e oportunidades de trabalho no meio rural. Deste modo, os agricultores familiares estarão capacitados a participar como pessoas físicas ou jurídicas, desde que sejam formados no mínimo por $90 \%$ desses agricultores e utilizarem no processo de produção no mínimo 70 \% da matéria prima própria do estabelecimento familiar.

No Estado do Maranhão, foi elaborada a Lei das Agroindústrias Familiares de Pequeno Porte (Lei Estadual no. 10.086/2014), com objetivo de implementação de estratégias governamentais para inclusão de produção agroindustrial de agricultores familiares nos mercados de produtos no Estado. Em sua defınição, a lei identifica a participação dos estabelecimentos de pequeno porte, familiares e artesanais nas atividades de agroindústrias. 0 objetivo dessa lei visa a estabelecer as estratégias na esfera estadual e a ajudar os produtores locais em melhorar a transformação de seus produtos e facilitar a comercialização, através de inserção no mercado formal de produtos. A medida prevê a motivação dos pequenos produtores na elaboração e comercialização de produtos de origens vegetal e animal, produzidos nos seus estabelecimentos. A mudança em relação à legislação anterior se refere “à maior flexibilização na formalização de estabelecimentos agroindustriais de até $250 \mathrm{~m}^{2}$, que antes tinham que atender às mesmas exigências sanitárias estabelecidas para grandes empresas”. Conforme a nova Lei, a infraestrutura de estabelecimentos e sua localização "poderá ser dentro da propriedade rural ou na zona urbana”, bem como, os seus proprietários estarão isentos de apresentação da Licença ambiental prévia (LP), limitando-se à Licença ambiental única de instalação (LI) e de operação (LO) (IMIRANTE.COM, 2014). 
No Art. $2^{\circ}$ das disposições preliminares da lei, são considerados três tipos de agroindústrias de pequeno porte:

I - Estabelecimento agroindustrial familiar: empreendimento de propriedade sob a gestão individual ou coletiva de agricultores familiares, nos termos do art. $3^{\circ}$ da Lei Federal $n^{\circ}$. 11.326 de 24 de julho de 2006, com área útil não superior a $250 \mathrm{~m} 2$ que por motivação de natureza econômica e social, visam a agregar valor aos produtos que não conseguem comercializar "in natura" e dispõem de instalações mínimas conforme critérios definidos no regulamento;

II - Estabelecimento agroindustrial de pequeno porte: empreendimento não dirigido por agricultores familiares, mas considerados equivalentes, com área útil construída não superior a $250 \mathrm{~m}^{2}$;

III - Estabelecimento agroindustrial artesanal: empreendimentos agroindustriais que trabalham o produto até a sua finalização, basica- mente com a matéria produzida em seus estabelecimentos ou mediante contrato de parceria utilizando-se, predominantemente do trabalho manual, respeitando as características tradicionais, culturais ou regionais do produto, com área útil não superior a $250 \mathrm{~m}^{2}$.

Para atender às exigências do Sistema Unificado de Atenção à Sanidade Agropecuária - Suasa (Decreto no. 5.741/2006), a lei estadual estabelece, através do seu regulamento, os requisitos e normas operacionais para a concessão de habilitação sanitária ao estabelecimento agroindustrial familiar de pequeno porte ou artesanal. Para que as agroindústrias de produtos de origem animal possam proceder com o registo no Serviço de Inspeção Estadual (SIE), o Decreto n ${ }^{\circ}$. 30.388, de 15 de outubro de 2014 dispõe a seguinte classificação para este fim, apresentada na tabela 1. 
TABELA 1- Classificação e perfil produtivo das agroindústrias rurais

\begin{tabular}{|c|c|c|}
\hline Agroindústria & Perfil produtivo & Definição de atividades \\
\hline \multirow[t]{2}{*}{ Leite e derivados } & Fábrica de laticínios & $\begin{array}{l}\text { Recepção de leite e creme para o preparo de qualquer produto } \\
\text { lácteo. }\end{array}$ \\
\hline & Entreposto de laticínios & $\begin{array}{l}\text { Recepção, toalete, maturação, classificação, fracionamento, acon- } \\
\text { dicionamento e armazenagem de leite e derivados. }\end{array}$ \\
\hline \multirow[t]{3}{*}{$\begin{array}{l}\text { Carne e } \\
\text { derivados }\end{array}$} & $\begin{array}{l}\text { Abate e industrialização } \\
\text { de pequenos animais }\end{array}$ & $\begin{array}{l}\text { Deve ser dotado de instalações com as dimensões e equipamentos } \\
\text { adequados para o abate, manipulação, elaboração, industrializa- } \\
\text { ção, preparo, conservação, armazenagem e expedição das carnes } \\
\text { de aves, coelhos e outros pequenos animais e seus derivados sob } \\
\text { variadas formas. Possuir as instalações de frio compativel com a } \\
\text { capacidade de abate. }\end{array}$ \\
\hline & $\begin{array}{l}\text { Abate e industrialização } \\
\text { de médios e grandes } \\
\text { animais }\end{array}$ & $\begin{array}{l}\text { Deve ser dotado de instalações com as dimensões e equipamentos } \\
\text { adequados para o abate, manipulação, elaboração, industrializa- } \\
\text { ção, preparo, conservação, armazenagem e expedição das carnes } \\
\text { de bovinos, bubalinos, suínos, ovinos, caprinos e outros grandes } \\
\text { e médios animais e seus derivados sob variadas formas. Possuir as } \\
\text { instalações de frio compatível com a capacidade de abate. }\end{array}$ \\
\hline & $\begin{array}{l}\text { Fábrica e entrepostos } \\
\text { de produtos cárneos }\end{array}$ & $\begin{array}{l}\text { Destina-se à armazenagem e industrialização de variadas espécies } \\
\text { de animais. Deve ser dotado de instalações de frio e equipamentos } \\
\text { para o seu funcionamento. }\end{array}$ \\
\hline \multirow[t]{2}{*}{$\begin{array}{l}\text { Pescado e } \\
\text { derivados }\end{array}$} & Entreposto de pescado & $\begin{array}{l}\text { Destina-se ao recebimento, manipulação, frigorificação e distri- } \\
\text { buição do pescado. Pode dispor ou não dispor as instalações para } \\
\text { o aproveitamento de produtos não comestíveis. }\end{array}$ \\
\hline & $\begin{array}{l}\text { Fábrica de conservas de } \\
\text { pescado }\end{array}$ & $\begin{array}{l}\text { Deve possuir as dependências próprias para a recepção e indus- } \\
\text { trialização do pescado por qualquer forma, com o aproveitamento } \\
\text { ou não dos subprodutos não comestíveis. }\end{array}$ \\
\hline \multirow[t]{2}{*}{ Mel e derivados } & Apiário & $\begin{array}{l}\text { Destina-se à extração, procedimento e classificação do mel e seus } \\
\text { derivados, limitado à produção própria. Pode dispor ou não de } \\
\text { instalações e equipamentos apropriados. }\end{array}$ \\
\hline & $\begin{array}{l}\text { Entreposto de mel e } \\
\text { cera de abelha }\end{array}$ & $\begin{array}{l}\text { Destina-se à recepção, classificação e industrialização de mel e da } \\
\text { cera de abelha. }\end{array}$ \\
\hline \multirow[t]{2}{*}{ Ovos e derivados } & Entreposto para ovos & $\begin{array}{l}\text { Destina-se à recepção, lavagem, ovoscopia, classificação, arma- } \\
\text { zenagem e expedição de ovos em natureza, oriundos de vários } \\
\text { fornecedores, facultando-se à operação de classificação de ovos } \\
\text { que chegam ao entreposto já classificados, acondicionados e } \\
\text { identificados, podendo ou não fazer a industrialização, desde que } \\
\text { disponha de equipamentos adequados para essa operação. }\end{array}$ \\
\hline & $\begin{array}{l}\text { Fábrica de conserva de } \\
\text { ovos }\end{array}$ & $\begin{array}{l}\text { Destina-se à recepção e processamento, preparo e embalagem } \\
\text { de ovos, devendo dispor de dependências apropriadas para estas } \\
\text { operações. }\end{array}$ \\
\hline
\end{tabular}

Fonte: (MARANHÃO, 2016) 


\section{Pluriatividade e agroindústrias rurais no Maranhão: caracterização baseada nos dados do Censo Agropecuário de 2006}

De acordo com os resultados divulgados no Censo Agropecuário de 2006 (IBGE, 2009), no estado do Maranhão, entre as atividades não agrícolas mais declaradas pelos agricultores residentes no meio rural, destaca-se a ocupação em agroindústria de produtos ou indústria de transformação, depois das atividades principais da agricultura e pecuária. Observa-se que, de um total de 58. 407 estabelecimentos agropecuários, 48. 451 (ou 82,95 \%) são de agricultura familiar, cujos produtores declararam estar ocupados em atividades pluriativas, ou seja, dedicavam uma parte do seu tempo em atividades remuneradas fora do seu estabelecimento, tanto agropecuárias (53, $2 \%$ ), como não agropecuárias $(43,8 \%)$. Desse total, só 3,0 \% se referiram à ocupação em atividades agrícolas e não agrícolas no mesmo tempo (Tab. 2).

TABELA 2 - Frequências relativas de ocupações pluriativas, por número de estabelecimentos

\begin{tabular}{|c|c|c|c|c|c|c|c|c|}
\hline \multirow{2}{*}{ Categoria } & \multicolumn{8}{|c|}{ Tipo de atividade } \\
\cline { 2 - 9 } & Total & $\%$ & Agrícola & $\%$ & $\begin{array}{c}\text { Não } \\
\text { agrícola }\end{array}$ & $\%$ & $\begin{array}{c}\text { Agrícola/ } \\
\text { Não agrícola }\end{array}$ & $\%$ \\
\hline Total & 58407 & 100 & 29260 & 50,1 & 27235 & 46,6 & 1912 & 3,3 \\
\hline Não familiar & 9956 & 17,05 & 3512 & 6,02 & 6050 & 10,36 & 394 & 0,7 \\
\hline Agricultura Familiar & 48451 & 82,95 & 25748 & 44,08 & 21185 & 36,27 & 1518 & 2,6 \\
\hline
\end{tabular}

Fonte: Censo Agropecuário de 2006: tabulação especial realizada pelo IBGE1. Elaboração da autora.

Da análise de dados, revela-se também que dentre as atividades não agrícolas, além da indústria de produtos agropecuários, foram identificadas as atividades relacionadas com a produção de produtos vegetais, criação de animais e produção de seus produtos, de turismo rural, prestação de serviços de beneficiamento, transformação e transporte, prestação de serviços para a empresa integradora, artesanato e tecelagem, e outros serviços.

A análise de ocupações não agrícolas segundo o tipo de atividade e volume das receitas obtidas demonstrou que o setor da agroindústria de transformação de produtos da agropecuária ocupa a terceira posição, depois de atividades de produção de vegetais $(63,47 \%)$ e criação de animais $(35,24$ $\%$ ), e teve a participação relativa de 18,42 $\%$, sendo que nestes setores foram obtidas as maiores receitas, em comparação com outras atividades não agrícolas. Assim, foi observado que de 38.891 estabelecimentos que declararam ter recebido receitas de produtos de agroindústrias, 36.361 foram da agricultura familiar (Tab. 3).

Estes dados serviram como ponto de partida para a análise mais detalhada do perfil produtivo das principais agroindústrias rurais no Estado, sendo baseados no Censo Agropecuário de 2006 (SIDRA/IBGE).

1. Para análise de pluriatividade e a elaboração das tabelas 2 e 3 , foram consultadas as tabelas de $n^{\circ}$. 1115 (Número de estabelecimentos agropecuários, na qual o produtor declarou ter atividades fora do es- 
TABELA 3 - Valores das receitas obtidas e participações relativas no ano (2006), por tipo da receita

\begin{tabular}{|c|c|c|c|c|c|c|}
\hline \multirow[t]{2}{*}{ Tipo de atividade } & \multicolumn{6}{|l|}{ Categoria } \\
\hline & $\begin{array}{c}\text { Total } \\
\text { (unidades) }\end{array}$ & $\%$ & Não familiar & $\%$ & Agricultura familiar & $\%$ \\
\hline Total (unidades) & 197407 & 100 & 18690 & 9,47 & 178717 & 90,53 \\
\hline Produção de produtos vegetais & 134477 & 68,12 & 9186 & 4,65 & 125291 & 63,47 \\
\hline $\begin{array}{l}\text { Criação de animais e produção } \\
\text { de seus produtos }\end{array}$ & 81736 & 41,4 & 12178 & 6,17 & 69558 & 35,24 \\
\hline Produtos de agroindústria & 38891 & 19,7 & 2530 & 1,28 & 36361 & 18,42 \\
\hline $\begin{array}{l}\text { Animais criados em cativeiro } \\
\text { (jacaré, escargô, capivara) }\end{array}$ & 600 & 0,3 & 111 & 0,06 & 489 & 0,25 \\
\hline Húmus & 121 & 0,06 & 6 & 0,00 & 115 & 0,06 \\
\hline Esterco & 218 & 0,11 & 84 & 0,04 & 134 & 0,07 \\
\hline Atividades de Turismo Rural & 35 & 0,02 & 12 & 0,01 & 23 & 0,01 \\
\hline Exploração mineral & 354 & 0,18 & 45 & 0,02 & 309 & 0,16 \\
\hline $\begin{array}{l}\text { Serviços de beneficiamento } \\
\text { e transformação de produtos } \\
\text { para terceiros }\end{array}$ & 3625 & 1,84 & 382 & 0,19 & 3243 & 1,64 \\
\hline $\begin{array}{l}\text { Prestação de serviços à empre- } \\
\text { sa integradora }\end{array}$ & 554 & 0,28 & 145 & 0,07 & 409 & 0,21 \\
\hline $\begin{array}{l}\text { Artesanato, tecelagem e outras } \\
\text { atividades não agrícolas }\end{array}$ & 1909 & 0,97 & 140 & 0,07 & 1769 & 0,9 \\
\hline
\end{tabular}

Fonte: Censo Agropecuário de 2006: tabulação especial realizada pelo IBGE. Elaboração da autora.

Considerou-se como principais aquelas agroindústrias que contaram com o maior número de estabelecimentos, utilizando os três indicadores que mais caracterizam o seu perfil produtivo: o número de estabelecimentos, a quantidade produzida e a quantidade de produto destinada à venda. Foram selecionadas para análise as agroindústrias de produtos de origem vegetal: farinha de mandioca, tapioca e arroz em grão; e das agroindústrias de produtos de origem animal: ligadas à produção de lei- te pasteurizado, carne tratada, embutidos e produção de pescado. A escolha de agroindústrias para análise é fundamentada pela sua importância no sistema de produção agroalimentar na comunidade, e pela maior participação da agricultura familiar nos valores agregados dos produtos processados.

Tendo em consideração que os dados apresentados no Censo só esclarecem a diferenciação entre a agricultura familiar e não familiar segundo variáveis selecionadas de produtos primários, não foi possível

tabelecimento no ano, por tipo de atividade e agricultura familiar), nº 1116 (Número de estabelecimentos agropecuários que obtiveram receitas e valor das receitas obtidas no ano por tipo de receita e agricultura familiar), disponibilizadas no Sistema de Recuperação Automática - SIDRA/IBGE. 
distinguir com muita exatidão a informação sobre as agroindústrias da agricultura familiar e não familiar. Contudo, os dados divulgados no Censo sobre o valor das receitas obtidas pelos estabelecimentos dos produtos de agroindústrias, com diferenciação entre a agricultura familiar e não familiar, permitem verificar de forma empírica que, as agroindústrias do Estado do Maranhão são na sua maioria do tipo familiar ou de pequeno porte. De todo modo, na análise serão consideradas as agroindústrias rurais (familiares e não familiares) sem especificar o seu tipo. Selecionamos para análise as agroindústrias de produtos de origem vegetal: farinha de mandioca, tapioca e arroz em grão e das agroindústrias de produtos de origem animal: aquelas ligadas à produção de leite pasteurizado, carne tratada, embutidos e produção de pescado.

0 Estado ocupa segunda posição, considerando-se o número do efetivo de bovinos 5.592 .007 cabeças $(22,1 \%)$, das quais de $2.322 .628(41,5 \%)$ da agricultura familiar, depois do estado de Bahia que conta com 10.229.459 cabeças $(40,4 \%)$ do total do efetivo bovino na região Nordeste. É também o segundo estado no Nordeste com maior número de efetivo de equinos - 149.939 cabeças (12,8 \%), depois do estado de Bahia que conta com 522.811 cabeças ou 44,6 \% de efetivo na região. Com relação ao número de estabelecimentos correspondente ao efetivo bovino, o Maranhão está em uma posição de quarto lugar, atrás dos estados de Bahia, Pernambuco e Ceará. Com relação ao número de estabelecimentos correspondente ao efetivo equino também está atrás dos estados de Bahia, Pernambuco e Ceará. Revela-se também, que no Maranhão o menor número de estabelecimentos de agricultura não familiar, somente 14.825 $(15,9 \%)$, criam a $58,4 \%$ do total de todo efetivo do gado bovino no estado.

0 Maranhão conta com o maior número, 1.629 de estabelecimentos (73,2 \%) e maior efetivo, 52.848 de bubalinos (67,5\%) em toda região Nordeste. Em nível nacional, com relação ao número de estabelecimentos do efetivo bubalino o Maranhão só está atrás de estado do Pará, que conta com 4.502 estabelecimentos.

De número total de estabelecimentos de bovinos são 16.537 que produziram naquele ano o leite de vaca e deles, 12.496 estabelecimentos são de agricultura familiar. Esses estabelecimentos em conjunto (familiares e não familiares) contaram com o efetivo 184.878 de cabeças de vacas ordenhadas, das quais foram obtidos 174.525 litros de leite. Dessa quantidade, 56,0 \% de leite foi produzido nos estabelecimentos da agricultura familiar. A quantidade de leite cru beneficiada no próprio estabelecimento constituiu 10.610 litros ou 6,1\% de quantidade total produzida. Observa-se, também, que o estado do Maranhão está com menor número de agroindústrias especializadas em produção de leite em toda região do Nordeste. No entanto, em relação do número de cabeças de vacas ordenhadas permanece em quinto lugar (7,6\%), depois dos estados de Bahia (34,6\%), Ceará (16,5 \%), Pernambuco (12,3\%) e Paraíba (8,6 \%).

A diferença significativa entre os indicadores de quantidade de leite produzida (174.525 mil litros) e beneficiada (10.610 mil litros) no próprio estabelecimento significa que este produto é usado principalmente no consumo da própria família e não é destinado à comercialização. Da análise, revela-se que no ano de 2006 o estado contou com 9.090 estabelecimentos que venderam 146.330 litros de leite cru e só 20 unidades que venderam 96 mil litros de leite pasteurizado. Em relação do produto 
de leite pasteurizado destinado à venda, o estado está com menores índices, depois do estado do Piauí. Estes números revelam a situação precária das agroindústrias especializadas na produção de leite e produtos derivados de leite no estado.

TABELA 4 - Indicadores de produção e venda de leite de vaca

\begin{tabular}{|c|c|c|c|c|c|c|}
\hline \multirow{2}{*}{\multicolumn{2}{|c|}{$\begin{array}{l}\text { Produtos de leite } \\
\text { Maranhão }\end{array}$}} & \multicolumn{5}{|c|}{ Região } \\
\hline & & Nordeste & Brasil & $\begin{array}{c}\text { MA/ } \\
\text { Nordeste, \% }\end{array}$ & \begin{tabular}{|c|}
$\mathrm{MA} /$ \\
Brasil, \% \\
\end{tabular} & \\
\hline \multicolumn{7}{|c|}{ Leite de vaca } \\
\hline \multicolumn{2}{|c|}{ Número de unidades } & 16.537 & 410.035 & 1.350 .809 & 4,03 & 1,22 \\
\hline \multicolumn{2}{|c|}{ Vacas ordenhadas (cab.) } & 184.878 & 2.411 .472 & 12.710 .701 & 7,7 & 1,5 \\
\hline \multicolumn{7}{|c|}{ Produção de leite } \\
\hline \multicolumn{2}{|c|}{ Total (mil litros) } & 174.525 & 2.725 .684 & 20.567 .500 & 6,4 & 0,8 \\
\hline \multicolumn{2}{|c|}{ Cru beneficiado } & 10.610 & 187.579 & 788.655 & 5,7 & 1,3 \\
\hline \multicolumn{7}{|c|}{ Venda de leite } \\
\hline \multirow[t]{2}{*}{ Cru } & Número de unidades & 9.090 & 184.109 & 874.576 & 4,9 & 1,0 \\
\hline & Quantidade vendida (mil litros) & 146.330 & 2.188 .852 & 18.724.770 & 6,7 & 0,8 \\
\hline \multirow[t]{2}{*}{ Pasteurizado } & Número de unidades & 20 & 244 & 2.429 & 8,2 & 0,04 \\
\hline & Quantidade vendida (mil litros) & 96 & 8.597 & 52.532 & 1,1 & 0,2 \\
\hline
\end{tabular}

Fonte: Censo Agropecuário de 2006: tabelas especiais realizadas pelo IBGE². Elaboração da autora.

Já em relação à agroindústria de leite de búfala, o estado revela melhores resultados em nível da região Nordeste. 0 Maranhão contou naquele ano com 325 de estabelecimentos (77,3\%) especializados em produção de leite de búfala, com 50,5 \% de leite produzido. Dessas unidades são 262 (74,9 $\%$ que venderam $47,4 \%$ de leite de toda quantidade vendida na região (Tab. 5).

Em nível nacional, as regiões do Norte e do Sudeste que revelaram os melhores resultados pelo número de agroindústrias especializadas em produção de leite, em particular, o estado do Pará, seguido de São Paulo. No estado do Pará, 890 de estabelecimentos de agroindústrias de leite produziram $24,5 \%$ de produto e no estado de São Paulo 376 de estabelecimentos produziram 22,4 \% do total produzido no país. Comparando com estes estados, no estado do Maranhão foi produzido 3,8 \% do total produzido no país. Em relação ao produto vendido foi observada a tendência um pouco diferente entre esses estados. No estado do Pará revelou-se um número maior de estabelecimentos que venderam o produto, mas a quantidade vendida $(22,8 \%)$ foi menor do que no estado de São Paulo, onde das 374 unidades de produção foi vendido $24,5 \%$ de produto do total vendido no país.

2. Para elaboração das tabelas 4 e 5 foram consultadas as tabelas especiais realizadas pelo IBGE e disponibilizadas no Sistema IBGE de Recuperação Automática - SIDRA/IBGE: Tabela 933: Produção e venda de leite de vaca nos estabelecimentos agropecuários, por condição do produtor em relação às terras, grupos de área total e grupos de cabeças de bovinos e tabela 959: Produção e venda de leite de búfala no ano nos estabelecimentos agropecuários por condição do produtor em relação às terras, grupos de cabeças, grupos de atividade econômica e grupos de área total. 
TABELA 5 - Indicadores de produção e venda de leite da búfala

\begin{tabular}{|l|c|c|c|c|c|c|}
\hline \multirow{2}{*}{ Região } & \multicolumn{3}{|c|}{ Produção de leite } & \multicolumn{2}{c|}{ Venda de leite } & \% Vendida/ \\
\cline { 2 - 6 } & $\begin{array}{c}\text { Número de } \\
\text { unidades de } \\
\text { produção }\end{array}$ & $\begin{array}{c}\text { Búfalas orde- } \\
\text { nhadas } \\
\text { (cabeças) }\end{array}$ & $\begin{array}{c}\text { Quantidade } \\
\text { produzida } \\
\text { (toneladas) }\end{array}$ & $\begin{array}{c}\text { Número de } \\
\text { unidades }\end{array}$ & $\begin{array}{c}\text { Quantidade } \\
\text { vendida } \\
\text { (toneladas) }\end{array}$ & Produzida \\
\hline Maranhão & 325 & 2.677 & 1.764 & 262 & 1.362 & 77,2 \\
\hline Nordeste & 420 & 4.855 & 3.491 & 350 & 2.874 & 82,3 \\
\hline Brasil & 2.796 & 48.864 & 45.955 & 2.571 & 38.087 & 82,9 \\
\hline MA/Nordeste, \% & 77,3 & 55,1 & 50,5 & 74,9 & 47,4 & - \\
\hline MA/Brasil, \% & 11,6 & 5,5 & 3,8 & 10,2 & 3,6 & - \\
\hline
\end{tabular}

Fonte: Censo Agropecuário de 2006: tabelas especiais realizadas pelo IBGE. Elaboração da autora.

Segundo os dados da pesquisa trimestral de leite (IBGE, 2017) foi observado que, nos últimos quatro anos (2013-2017), no estado do Maranhão, houve algumas variações em relação da quantidade de leite cru, resfriado ou não, adquirido e industrializado, segundo o tipo de inspeção sanitária, como é demonstrado na tabela 6. Verifica-se a queda brusca no ano de 2015 na aquisição e industrialização de leite comparado com os anos anteriores (2013-2014), principalmente nas agroindústrias com Inspeção Sanitária Federal, o que influenciou a diminuição nos indicadores de comercialização nos mercados fora do estado. Nos anos de 2016 e 2017, os valores começaram subir, mas ainda não atingiram os mesmos demonstrados em 2014.

TABELA 6 - Quantidade de leite cru, resfriado ou não, adquirido e industrializado, segundo o tipo de inspeção (mil litros)

\begin{tabular}{|l|r|r|r|r|r|}
\hline \multirow{2}{*}{ Tipo de inspeção } & \multicolumn{6}{c|}{ Trimestre } \\
\cline { 2 - 6 } & \multicolumn{7}{|c|}{$4^{\circ} .2013$} & \multicolumn{1}{c|}{$4^{\circ} .2014$} & $4^{\circ} .2015$ & $4^{\circ} .2016$ & $3^{\circ} .2017$ \\
\hline Total & 20.930 & \multicolumn{7}{|c|}{ Leite adquirido } \\
\hline Federal & 16.428 & 21.435 & 8.838 & 13.867 & 15.159 \\
\hline Estadual & 4.113 & 16.169 & 5.035 & 9.336 & 9.907 \\
\hline Municipal & 389 & 4.714 & 3.571 & 4.138 & 4.684 \\
\hline & & 552 & 234 & 393 & 568 \\
\hline Total & 20.930 & 21.259 & 8.838 & 13.866 & 15.159 \\
\hline Federal & 16.428 & 15.993 & 4.296 & 8.310 & 8.878 \\
\hline Estadual & 4.113 & 4.000 & 3.596 & 4.585 & 4.834 \\
\hline Municipal & 389 & 739 & 388 & 393 & 568 \\
\hline
\end{tabular}

Fonte: SIDRA/IBGE/Pesquisa trimestral

Em relação a produtos de carne e seus derivados: carne verde, tratada e embutidos, os dados são apresentados em tabelas 7, 8 e 9 e demonstram a situação de agroindústrias a nível nacional e a nível da região Nordeste e seus estados, e no estado do Maranhão. Na região do Nordeste se encontra a maioria de estabelecimentos agroindustriais de tratamento da carne, 824 o que constitui 52,1 \% em nível do país, localizadas na maioria em três estados, no Maranhão estão 279, no estado de Piauí 362 e no estado de Bahia 148 agroindústrias. 
Tabela 7 apresenta os dados em relação de número de estabelecimentos, as quantidades produzidas (de matéria-prima do próprio estabelecimento e adquirida) e vendidas de carnes verdes, somando as de bovinos, suínos e de outros animais, bem como, a percentagem da quantidade de produto vendida em relação à quantidade produzida. Os dados da tabela 7 demonstram que, embora o estado do Maranhão ocupe a quinta posição pelo número de estabelecimentos agroindustriais que trabalham com este produto, revela os melhores índices de produção - 3.783 t (49,8%) com a utilização de matéria-prima do próprio estabelecimento e a quantidade vendida do produto $(32,9 \%)$ em nível de região Nordeste. No entanto, a relação entre a venda e a produção é menor do que em outros estados da região.

TABELA 7 - Número de agroindústrias, quantidades produzidas e vendidas de carne verde

\begin{tabular}{|c|c|c|c|c|c|}
\hline \multirow[t]{2}{*}{ Região } & \multirow[t]{2}{*}{$\begin{array}{l}\text { Número de } \\
\text { unidades }\end{array}$} & \multicolumn{2}{|c|}{$\begin{array}{c}\text { Quantidade produzida com } \\
\text { matéria prima (ton.) }\end{array}$} & \multirow{2}{*}{$\begin{array}{l}\text { Quantidade } \\
\text { vendida } \\
\text { (ton.) }\end{array}$} & \multirow[t]{2}{*}{$\begin{array}{l}\text { \% Vendida/ } \\
\text { Produzida }\end{array}$} \\
\hline & & própria & adquirida & & \\
\hline \multicolumn{6}{|c|}{ Carnes verdes (bovinos, suínos e outros animais) } \\
\hline Maranhão & 1.842 & 3.783 & 82 & 2.324 & 60,1 \\
\hline Piauí & 5.879 & 706 & 223 & 677 & 72,9 \\
\hline Ceará & 3.475 & 671 & 159 & 628 & 75,7 \\
\hline Rio Grande do Norte & 209 & 128 & 164 & 287 & 98,3 \\
\hline Paraiba & 639 & 398 & 260 & 642 & 97,6 \\
\hline Pernambuco & 2.808 & 548 & 288 & 674 & 80,6 \\
\hline Alagoas & 308 & 59 & 14 & 58 & 79,6 \\
\hline Sergipe & 84 & 92 & 54 & 130 & 89,0 \\
\hline Bahia & 2.997 & 1.206 & 598 & 1.649 & 91,4 \\
\hline Nordeste & 18.241 & 7.589 & 1.840 & 7.071 & 75,0 \\
\hline Brasil & 209.490 & 58.296 & 8.977 & 21.337 & 31,7 \\
\hline MA/Nordeste, $\%$ & 10,1 & 49,8 & 4,5 & 32,9 & - \\
\hline MA/Brasil, \% & 0,9 & 6,5 & 0,9 & 10,9 & $x$ \\
\hline
\end{tabular}

Fonte: Censo Agropecuário de 2006: tabulação realizada pelo IBGE ${ }^{3}$. Elaboração da autora.

Em nível nacional, 57,1 \% de carne tratada foi produzida na região Nordeste, desse volume no Maranhão foi produzido 13,0 \% e no estado de Bahia 52,4\%. No ano de 2006 no Maranhão foi produzido $37 \mathrm{t}$ de carne, delas
36 t de matéria prima própria do estabelecimento. Observou-se que só $10 \mathrm{t}$ do produto foi destinado à venda. Comparado com as agroindústrias do estado de Bahia, onde nesse ano foi produzido 142 t (96 t de matéria prima ad-

3. Para elaboração de tabelas 7, 8 e 9 sobre agroindústrias rurais foram consultadas as tabelas especiais elaboradas pelo IBGE e disponibilizadas no Sistema de Recuperação Automática- SIDRA/IBGE. Tabela 4081: Produção, Venda e Valor da Produção na agroindústria rural por produtos da agroindústria rural, tipo de instalação e grupos de área total e Tabela 827: Produção, Venda e Valor de produção na agroindústria rural, condição do produtor em relação às terras, grupos de atividade econômica e destino da produção. 
quirida de outro produtor) e vendido $138 \mathrm{t}$ de carne tratada. No estado de Piauí, embora estejam localizadas a maioria das agroindústrias na região, o índice de produção constituiu $36 \mathrm{t}$ das quais 27 ta matéria prima própria e produto que foi vendido constituiu de 9 t (Tab. 8).

Em relação de embutidos, produtos derivados de carnes bovinas, suínas e de aves, observa-se a situação diferente. No estado do Maranhão foram identificadas três agroindústrias que produziram 18 t de pro- dutos, utilizando a matéria prima do próprio estabelecimento e venderam 6 t. No estado da Bahia, 18 estabelecimentos agroindustriais produziram $9 \mathrm{t}$ e venderam $7 \mathrm{t}$ de embutidos (Tab. 9). No entanto, verifica-se que estas atividades se concentram mais na região do Sul do país e, principalmente no estado de Rio Grande de Sul, onde estão localizadas 14.758 agroindústrias de produção de embutidos ou 83,3 \% de todas as agroindústrias localizadas no território brasileiro.

TABELA 8 - Número de agroindústrias, quantidades produzidas e vendidas de carne tratada

\begin{tabular}{|c|c|c|c|c|c|}
\hline \multirow[t]{2}{*}{ Região } & \multirow[t]{2}{*}{$\begin{array}{l}\text { Número de } \\
\text { unidades }\end{array}$} & \multicolumn{2}{|c|}{$\begin{array}{c}\text { Quantidade produzida com } \\
\text { matéria prima (ton.) }\end{array}$} & \multirow{2}{*}{$\begin{array}{c}\text { Quantidade } \\
\text { vendida } \\
\text { (ton.) }\end{array}$} & \multirow[t]{2}{*}{$\begin{array}{l}\text { \% Vendida/ } \\
\text { Produzida }\end{array}$} \\
\hline & & própria & adquirida & & \\
\hline \multicolumn{6}{|c|}{ Carne tratada (sol e salgada) } \\
\hline Maranhão & 279 & 36 & 1 & 10 & 27,0 \\
\hline Piauí & 362 & 27 & 9 & 9 & 25,0 \\
\hline Ceará & 9 & 1 & - & 1 & 100 \\
\hline Rio Grande do Norte & 4 & 0 & 4 & 4 & 100 \\
\hline Paraíba & 5 & 25 & 4 & 28 & 96,6 \\
\hline Pernambuco & 12 & 2 & 0 & 1 & 50,0 \\
\hline Alagoas & 2 & $x^{4}$ & - & - & - \\
\hline Sergipe & 3 & 16 & 5 & 21 & 100 \\
\hline Bahia & 148 & 46 & 96 & 138 & 97,2 \\
\hline Nordeste & 824 & 152 & 119 & 211 & 78,9 \\
\hline Brasil & 1.582 & 276 & 199 & 315 & 66,3 \\
\hline MA/Nordeste, $\%$ & 33,9 & 23,7 & 0,8 & 4,7 & - \\
\hline MA/Brasil, \% & 17,6 & 13,0 & 0,5 & 3,2 & - \\
\hline
\end{tabular}

Fonte: Censo Agropecuário de 2006: tabulação realizada pelo IBGE. Elaboração da autora.

No ano de 2006, foi produzido 62,7 \% e vendido 48,8\% de produtos cárneos no nível nacional. 70,6 \% de produção foi realizada com utilização de matéria prima própria. Contudo, os resultados de pesquisa de Waquil et al. (2014) revelam que na região do Sul,
93,5 \% dos estabelecimentos que processaram os embutidos não comercializaram o produto.

A venda dos produtos cárneos depende da participação dos mercados de vários níveis, municipal, estadual ou federal, o que exige ter o registro do estabelecimento nos

4. Os dados das unidades territoriais com menos de 3 (três) informantes estão desidentificados com o caráter x (nota do IBGE). Foram consultadas tabelas especiais 1092, 1093 e 1094 disponibilizadas no Sistema de recuperação automática - SIDRA/IBGE. 
Serviços de inspeção sanitária ofıcial: municipal (SIM), estadual (SIE) e federal (SIF). São os serviços de fiscalização e inspeção sanitária realizados pelos órgãos ofıciais dos governos federal, estadual e municipal, que exercem o controle sanitário e tecnológico de produtos de origem animal.

TABELA 9 - Número de agroindústrias, quantidades produzidas e vendidas de embutidos

\begin{tabular}{|c|c|c|c|c|c|}
\hline \multirow[t]{2}{*}{ Região } & \multirow[t]{2}{*}{$\begin{array}{r}\text { Número de } \\
\text { unidades }\end{array}$} & \multicolumn{2}{|c|}{$\begin{array}{c}\text { Quantidade produzida com } \\
\text { matéria prima (ton.) }\end{array}$} & \multirow{2}{*}{$\begin{array}{l}\text { Quantidade } \\
\text { vendida } \\
\text { (ton.) }\end{array}$} & \multirow[t]{2}{*}{$\begin{array}{l}\text { \% Vendida/ } \\
\text { Produzida }\end{array}$} \\
\hline & & própria & adquirida & & \\
\hline \multicolumn{6}{|c|}{ Embutidos (linguiças, salsichas e outros produtos) } \\
\hline Maranhão & 3 & 18 & 0 & 6 & 33,3 \\
\hline Piauí & 4 & 1 & 0 & 1 & 100 \\
\hline Ceará & 3 & 1 & - & 1 & 100 \\
\hline Rio Grande do Norte & 2 & - & $x$ & $x$ & - \\
\hline Paraíba & 1 & $X$ & $\mathrm{x}$ & $\mathrm{x}$ & - \\
\hline Pernambuco & 1 & $\mathrm{X}$ & $\mathrm{x}$ & - & - \\
\hline Alagoas & 1 & $x$ & $x$ & - & - \\
\hline Sergipe & - & - & - & - & - \\
\hline Bahia & 15 & 7 & 2 & 7 & 77,8 \\
\hline Nordeste & 30 & 29 & 7 & 21 & 58,3 \\
\hline Brasil & 17.772 & 1.854 & 1.099 & 1.811 & 61,3 \\
\hline MA/Nordeste, $\%$ & 10,0 & 62,1 & 0,0 & 28,6 & - \\
\hline MA/Brasil, \% & 0,02 & 1,0 & 0,0 & 0,3 & \\
\hline
\end{tabular}

Fonte: Censo Agropecuário de 2006: tabulação realizada pelo IBGE. Elaboração da autora.

No território nacional brasileiro estes serviços começaram o seu funcionamento após a promulgação da Lei federal $\mathrm{n}^{\circ}$. 7.889, de 23 de novembro de 1989 através das suas competências em vários níveis. SIF-MAPA é responsável pelo registro dos produtos que são comercializados entre os diversos estados. SIE-MA/AGED é responsável pelo registro dos produtos que são comercializados dentro do estado do Mara- nhão. SIM- Secretarias Municipais de Agricultura são responsáveis pelo registro dos produtos que são comercializados dentro dos municípios do estado.

Na tabela 10 são apresentados os dados sobre o número de estabelecimentos agroindústrias, por tipos de rebanho e tipo de inspeção no estado do Maranhão. Estes dados demonstram a situação da indústria dos produtos cárneos no estado do Maranhão. 
TABELA 10 - Número de estabelecimentos de abate, por tipo de rebanho e tipo de inspeção

\begin{tabular}{|c|c|c|c|c|}
\hline \multirow[t]{2}{*}{ Tipo de inspeção } & \multicolumn{4}{|c|}{ Ano e trimestre } \\
\hline & $4^{\circ} .2000$ & $4^{\circ} .2006$ & $4^{\circ} .2016$ & $3^{\circ} .2017$ \\
\hline \multicolumn{5}{|c|}{ Bovinos } \\
\hline Total & 20 & 43 & 49 & 48 \\
\hline Federal & 3 & 5 & 3 & 3 \\
\hline Estadual & 1 & 1 & 1 & 1 \\
\hline Municipal & 16 & 37 & 45 & 44 \\
\hline \multicolumn{5}{|c|}{ Suinos } \\
\hline Total & 3 & 5 & 3 & 3 \\
\hline Federal & 1 & 1 & - & - \\
\hline Estadual & - & - & - & - \\
\hline Municipal & 2 & 4 & 3 & 3 \\
\hline \multicolumn{5}{|c|}{ Frangos } \\
\hline Total & - & - & 5 & 5 \\
\hline Federal & - & - & - & - \\
\hline Estadual & - & - & 1 & 1 \\
\hline Municipal & - & - & 4 & 4 \\
\hline
\end{tabular}

Fonte: IBGE: tabelas especiais ${ }^{5}$

Como demonstram os dados da tabela 10 , ao longo de quase duas décadas, o número de estabelecimentos de abate de bovinos aumentou de 20, no ano de 2000 até 48, no ano de 2017. Contudo, esse aumento se refere ao mercado municipal, pois em nível do mercado federal observou-se o aumento de dois estabelecimentos no ano de 2006, mas no ano de 2016, só três sobreviveram. No nível do mercado estadual não houve alterações. Estes dados significam que a maior parte dos produtores de carne no estado só têm o acesso aos mercados nos seus municípios, para comercializar os seus produtos.
Em relação à carne suína, observou-se que, no período de 2000 a 2006, existiu só uma agroindústria de abate com vendas em nível do mercado federal e, que deixou de funcionar nos anos de 2016 e 2017 . No ano de 2006 tinham funcionado quatro estabelecimentos de abate de suínos, e nos últimos anos este número diminuiu até três estabelecimentos. Em relação da carne de aves, observa-se o funcionamento de um estabelecimento a nível estadual e quatro estabelecimentos a nível municipal, nos anos de 2016 e 2017.

Outro produto que está relacionado com a segurança alimentar no estado é o

5. Foram consultadas tabelas especiais 1092, 1093 e 1094 disponibilizadas no Sistema de recuperação automática - SIDRA/IBGE. 
pescado. Os dados do Censo Agropecuário de 2006 demonstraram que, em nível da região Nordeste, o estado do Maranhão contou com o maior número de estabelecimentos de pescado especializados em beneficiamento e comercialização, no entanto, estava atrás do estado do Ceará pelas quantidades de produto produzidas e vendidas. No ano de 2006, nos 1.799 estabelecimentos localizados no Maranhão e que constituíram 28,8 \% do total dos estabelecimentos na região, foi produzido $21,1 \%$ de pescado e os 1.415 (32,8\%), que destinaram a 19,3\% dos seus produtos à venda do total vendido, comparado com os outros estados, cedendo apenas ao estado de Bahia, que produziu 26,6 \% e vendeu 23,6 \% de pescado do total produzido e vendido na região (Tab. 11).

TABELA 11 - Indicadores de produção e venda de pescado

\begin{tabular}{|c|c|c|c|c|c|}
\hline \multirow[t]{2}{*}{ Região } & \multirow{2}{*}{$\begin{array}{l}\text { Unidades de } \\
\text { produção } \\
\text { (total) }\end{array}$} & \multicolumn{2}{|c|}{ Produção } & \multicolumn{2}{|c|}{ Venda } \\
\hline & & $\mathrm{N}^{\circ}$. unidades & $\begin{array}{c}\text { Quantidade, } \\
(\mathrm{kg})\end{array}$ & $\mathrm{N}^{\circ}$. unidades & $\begin{array}{l}\text { Quantidade, } \\
(\mathrm{kg})\end{array}$ \\
\hline Brasil & 56.818 & 56.818 & 108.107 .387 & 19.841 & 94.343 .706 \\
\hline Nordeste & 6.256 & 6.256 & 28.438 .442 & 4.312 & 27.127 .352 \\
\hline Maranhão & 1.799 & 1.799 & 6.003 .689 & 1.415 & 5.238 .934 \\
\hline Piauí & 588 & 588 & 1.973 .689 & 473 & 1.605 .631 \\
\hline Ceará & 627 & 627 & 7.553 .846 & 477 & 6.400 .355 \\
\hline Rio Grande do Norte & 276 & 276 & 1.267 .548 & 220 & 1.609 .595 \\
\hline Paraíba & 563 & 563 & 2.129 .110 & 407 & 2.050 .112 \\
\hline Pernambuco & 513 & 513 & 1.152 .981 & 257 & 1.029 .796 \\
\hline Alagoas & 399 & 399 & 2.424 .782 & 269 & 2.945 .586 \\
\hline Sergipe & 571 & 571 & 1.596 .163 & 380 & 1.509 .681 \\
\hline Bahia & 920 & 920 & 4.336 .336 & 414 & 4.737 .662 \\
\hline MA/Nordeste, $\%$ & 28,8 & 28,8 & 21,1 & 32,8 & 19,3 \\
\hline MA/Brasil, \% & 3,2 & 3,2 & 5,6 & 7,1 & 5,6 \\
\hline
\end{tabular}

Fonte: Censo Agropecuário de 2006: tabelas especiais realizadas pelo IBGE ${ }^{6}$. Elaboração da autora.

Segundo os dados, em todo Brasil no ano de 2006 foi produzido 1. 332. $874 \mathrm{t}$ de farinha de mandioca e a maior parte foi produzida nas regiões do Nordeste e Norte, respectivamente 50,4 \% e 46,9\% do total produzido no país. Na região do Nordeste estão localizados 177. 655 de unidades de agroindústrias ou 67,1 \% do total de estabelecimentos no país. Desse número, são 47.030 (26,5 \%) que estão localizadas no estado do Maranhão e produziram 254.830 t de farinha de mandioca, das quais 234.445 t ou 92,0 \% foram beneficiadas de matéria prima própria do estabelecimento. 0 fato,

6. Para a elaboração de tabela 11 foi consultada a tabela 972 do Sistema de recuperação automática - SIDRA/ IBGE: Movimento da aquicultura no ano nos estabelecimentos agropecuários por condição do produtor em relação às terras, grupos de área de espelho d'água, ambiente da criação e grupos de atividade econõmica. 
que dos 78.728 de estabelecimentos que produzem a mandioca no estado $94,3 \%$ de estabelecimentos são de agricultura familiar
(Tab. 12), pode se considerar que as agroindústrias de farinha de mandioca, goma e tapioca são de pequeno porte ou familiares.

TABELA 12 - Número de agroindústrias, quantidades produzidas e vendidas de farinha de mandioca

\begin{tabular}{|c|c|c|c|c|c|}
\hline \multirow[t]{2}{*}{ Região } & \multirow{2}{*}{$\begin{array}{l}\text { Número de } \\
\text { unidades de } \\
\text { produção }\end{array}$} & \multicolumn{2}{|c|}{$\begin{array}{c}\text { Quantidade produzida com a } \\
\text { matéria-prima (ton.) }\end{array}$} & \multirow{2}{*}{$\begin{array}{l}\text { Quantidade } \\
\text { vendida } \\
\text { (ton.) }\end{array}$} & \multirow[t]{2}{*}{$\begin{array}{l}\text { \% Vendida/ } \\
\text { Produzida }\end{array}$} \\
\hline & & própria & adquirida & & \\
\hline Maranhão & 47.030 & 234.445 & 20.385 & 133.678 & 52,5 \\
\hline Piauí & 14.345 & 17.881 & 1.117 & 9.803 & 51,6 \\
\hline Ceará & 16.747 & 31.324 & 2.771 & 17.225 & 50,5 \\
\hline Rio Grande do Norte & 516 & 2.829 & 3.625 & 5.689 & 81,1 \\
\hline Paraíba & 3.078 & 3.967 & 1.529 & 3.166 & 57,6 \\
\hline Pernambuco & 6.775 & 17.351 & 5.721 & 15.953 & 69,1 \\
\hline Alagoas & 5.978 & 23.832 & 2.892 & 12.289 & 46,0 \\
\hline Sergipe & 6.176 & 26.033 & 7.663 & 27.499 & 81,6 \\
\hline Bahia & 77.010 & 234.234 & 34.121 & 181.754 & 67,7 \\
\hline Nordeste & 177.655 & 591.896 & 79.823 & 407.057 & 60,6 \\
\hline Brasil & 264.882 & 1.193 .214 & 139.660 & 948.190 & 71,1 \\
\hline MA/Nordeste, $\%$ & 26,5 & 39,6 & 25,5 & 32,8 & - \\
\hline MA/Brasil, \% & 17,7 & 19,6 & 14,6 & 14,1 & - \\
\hline
\end{tabular}

Fonte: Censo Agropecuário de 2006: tabulação realizada pelo IBGE7 . Elaboração da autora.

À venda, foi destinado 52,5\% de quantidade total produzida desse produto. Em nível da região, no estado da Bahia se concentra o maior número de produtores de farinha de mandioca, são 77.010 estabelecimentos. Neste estado, embora, não difere muito do Maranhão pela quantidade produzida, 268.355 t, o índice de produto destinado à venda foi maior e constituiu 67,6 \% da quantidade produzida, o que contribuiu para o aumento de percentagem de produto vendido em nível da região do Nordeste (60,6 \%) (Tab. 12). Em nível nacional destacou-se o estado do Pará, os seus 41.906 estabelecimentos agroindustriais produziram
508.421 t de produto, das quais são 475.707 t de matéria prima própria e a quantidade de 427.358 t foi destinada à venda. Nesse estado, os produtores venderam 84,1\% da quantidade de produto produzida.

Não se observa a mesma tendência com as agroindústrias de tapioca e goma, os produtos derivados de mandioca, embora, a região Nordeste se destaca pela quantidade de produção de 78,1 \% de produto em nível nacional (Tab. 13). Em nível do Nordeste, o Maranhão está em quarto lugar com $11,6 \%$ de produto produzido, depois dos estados da Bahia (44,4\%), Piauí (25,6 \%) e Ceará (16,0 \%).

7. Para elaboração das tabelas 12, 13 e 14, sobre agroindústrias rurais foram consultadas as tabelas especiais elaboradas pelo IBGE e disponibilizadas no Sistema de Recuperação Automática- SIDRA/IBGE. Tabela 4081: Produção, Venda e Valor da Produção na agroindústria rural por produtos da agroindústria rural, tipo de instalação e grupos de área total e Tabela 827: Produção, Venda e Valor de produção na agroindústria rural, condição do produtor em relação às terras, grupos de atividade econômica e destino da produção. 
TABELA 13 - Número de agroindústrias, quantidades produzidas e vendidas de goma ou tapioca

\begin{tabular}{|c|c|c|c|c|c|}
\hline \multirow[t]{2}{*}{ Região } & \multirow{2}{*}{$\begin{array}{c}\text { Número de } \\
\text { unidades de } \\
\text { produção }\end{array}$} & \multicolumn{2}{|c|}{$\begin{array}{c}\text { Quantidade produzida com a } \\
\text { matéria-prima (ton.) }\end{array}$} & \multirow{2}{*}{$\begin{array}{l}\text { Quantidade } \\
\text { vendida } \\
\text { (ton.) }\end{array}$} & \multirow[t]{2}{*}{$\begin{array}{l}\text { \% Vendida/ } \\
\text { Produzida }\end{array}$} \\
\hline & & própria & adquirida & & \\
\hline Maranhão & 3.316 & 3.783 & 466 & 3.362 & 79,1 \\
\hline Piauí & 11.115 & 8.937 & 458 & 4.932 & 52,5 \\
\hline Ceará & 7.452 & 5.576 & 280 & 2.173 & 37,1 \\
\hline Rio Grande do Norte & 121 & 127 & 114 & 215 & 89,2 \\
\hline Paraiba & 156 & 15 & 72 & 78 & 89,7 \\
\hline Pernambuco & 311 & 256 & 88 & 322 & 93,6 \\
\hline Alagoas & 128 & 16 & 1 & 14 & 82,4 \\
\hline Sergipe & 39 & 129 & 73 & 201 & 99,5 \\
\hline Bahia & 8.464 & 14.394 & 1.861 & 10.765 & 66,2 \\
\hline Nordeste & 31.102 & 33.232 & 3.412 & 22.062 & 60,2 \\
\hline Brasil & 40.251 & 40.991 & 5.911 & 30.736 & 65,5 \\
\hline MA/Nordeste, \% & 10,7 & 11,4 & 13,7 & 15,2 & - \\
\hline MA/Brasil, \% & 8,2 & 9,2 & 7,8 & 10,9 & - \\
\hline
\end{tabular}

Fonte: Censo Agropecuário de 2006: tabulação realizada pelo IBGE. Elaboração da autora.

Quanto ao número de estabelecimentos, de um total de 40.251 que foram identificados no Brasil, 77,3 \% (31.102) estão localizados no Nordeste, deles no Maranhão 3.316, o que corresponde 10,7 \%, enquanto nos estados da Bahia 8.464 (27,2 \%), Piauí 11.115 (35,7 \%) e Ceará 7.452 (24,0\%). Em relação à quantidade vendida de tapioca, observa-se que no Maranhão os produtores destinam a maior parte do produto à venda, o que corresponde 79,1 \% de toda quantidade produzida, comparado com o estado de Bahia 66,2 \%, Piauí 52,5 \% e Ceará $37,1 \%$. Os estados que vendem este produto quase na totalidade de produção são os de
Sergipe, Pernambuco, Paraíba e Rio Grande de Norte.

0 Maranhão se destaca também pelos indicadores de produção de arroz em grão (Tab. 14). Conta com o maior número 18.727 de estabelecimentos que constituem 54,1\% em nível da região de Nordeste e 45,1 \% em nível nacional. A quantidade produzida no ano de 2006 constituiu 46.226 t ou 71,5\% em nível da região e 42,9\% no nível nacional. Desse total, 39.934 t ou $86,4 \%$ foram produzidas de matéria prima própria de estabelecimento. 
TABELA 14 - Número de agroindústrias, quantidades produzidas e vendidas de arroz em grão

\begin{tabular}{|c|c|c|c|c|c|}
\hline \multirow[t]{2}{*}{ Região } & \multirow{2}{*}{$\begin{array}{l}\text { Número de } \\
\text { unidades de } \\
\text { produção }\end{array}$} & \multicolumn{2}{|c|}{$\begin{array}{c}\text { Quantidade produzida com a } \\
\text { matéria-prima (ton.) }\end{array}$} & \multirow{2}{*}{$\begin{array}{l}\text { Quantidade } \\
\text { vendida } \\
\text { (ton.) }\end{array}$} & \multirow[t]{2}{*}{$\begin{array}{l}\text { \% Vendida/ } \\
\text { Produzida }\end{array}$} \\
\hline & & própria & adquirida & & \\
\hline Maranhão & 18.727 & 39.934 & 6.292 & 9.145 & 19,8 \\
\hline Piauí & 12.615 & 9.756 & 1.612 & 888 & 7,8 \\
\hline Ceará & 1.892 & 4.665 & 1.147 & 307 & 5,3 \\
\hline Rio Grande do Norte & 116 & 56 & 7 & 12 & 19,0 \\
\hline Paraíba & 383 & 205 & 13 & 18 & 8,3 \\
\hline Pernambuco & 14 & 180 & 120 & 259 & 86,3 \\
\hline Alagoas & 9 & 71 & 12 & 82 & 98,8 \\
\hline Sergipe & 5 & 46 & - & 46 & 100 \\
\hline Bahia & 827 & 474 & 31 & 114 & 22,6 \\
\hline Nordeste & 34.588 & 55.387 & 9.235 & 10.870 & 16,8 \\
\hline Brasil & 41.509 & 86.856 & 20.984 & 44.672 & 41,4 \\
\hline MA/Nordeste, $\%$ & 54,1 & 72,1 & 68,1 & 84,1 & - \\
\hline MA/Brasil, \% & 45,1 & 46,0 & 30,0 & 20,5 & - \\
\hline
\end{tabular}

Fonte: Censo Agropecuário de 2006: tabulação realizada pelo IBGE. Elaboração da autora.

A exploração de rizicultura é praticada nas unidades de produção chamadas "roças” (MALUF, 1977), que são as lavouras temporárias com predominância de trabalho familiar e donde provém quase a totalidade $(93,3 \%)$ de arroz em casca, em comparação com 6,7 \% desse produto que provém das unidades não familiares. Assim, consideramos que o tipo de agroindústria de produção de arroz em grão é também familiar ou de pequeno porte.

Em relação à quantidade de produto vendida em nível da região, o Maranhão demonstrou os melhores índices que correspondem a 9.145 t ou $84,1 \%$ de produto. No entanto, o fato de que de $46.226 \mathrm{t}$ de arroz produzido pelas agroindústrias só $9.145 \mathrm{t}$ ou $19,8 \%$ foi destinado à venda demonstra que este produto é produzido pela maioria dos estabelecimentos para ser destinado ao consumo próprio, como se verifica na tabela 14 .

Em relação com o nível nacional, os dois estados que se destacaram pelas quan- tidades de arroz vendidas, são os estados do Rio Grande do Sul e Pará. No estado do Rio Grande do Sul da quantidade total produzida $19.604 \mathrm{t}$, foi destinado à venda 18.784 t do produto e no Pará de 13.255 t do produto, foi vendido 11.433 t. Observa-se que no estado do Pará 73,6 \% de produção foi realizada com a matéria prima adquirida, enquanto, no Rio Grande do Sul a produção foi realizada com 97,8 \% de matéria prima própria do estabelecimento. Foi observado também que, pela quantidade produzida de arroz em casca o Maranhão só cedeu ao estado do Rio Grande de Sul, embora conte com o número de estabelecimentos muito maior. 0 que se observou no estado de RS é que, dos 11.967 estabelecimentos especializados em produção de cultura de arroz em casca são 4.790 da agricultura não familiar, que produziram 89,3\% de produto. Sendo assim, ao contrário do estado do Maranhão, a produção de arroz nesse estado é uma atividade preferencialmente da agricultura não familiar. Ainda se observa que, neste 
estado, 93,6 \% da quantidade produzida foi destinada à comercialização (IBGE, 2009).

Analisando os dados estatísticos mais recentes ${ }^{8}$, apresentados na tabela 15 observou-se que no estado do Maranhão no pe- ríodo de 2006 a 2016 diminuíram consideravelmente as áreas plantadas de arroz e da mandioca, o que influenciou na diminuição das quantidades produzidas.

TABELA 15 - Área plantada, quantidade produzida e rendimento médio de arroz em casca e mandioca

\begin{tabular}{|l|c|c|c|c|c|c|}
\hline \multirow{2}{*}{ Indicadores } & \multicolumn{4}{|c|}{ Período do tempo } \\
\cline { 2 - 7 } & \multicolumn{2}{|c|}{2006} & \multicolumn{4}{c|}{2016} \\
\cline { 2 - 7 } & Arroz em casca & Mandioca & Arroz em casca & \multicolumn{2}{c|}{ Mandioca } \\
\cline { 2 - 7 } & Medida & Medida & Medida & $+/-2006$ & Medida & $+/-2006$ \\
\hline Área plantada/colhida, ha & 507.446 & 212.096 & 168.407 & -339.039 & 157.158 & -54.938 \\
\hline Quantidade produzida, t & 702.224 & 1.720 .322 & 152.216 & -550.008 & 1.305 .850 & -414.472 \\
\hline $\begin{array}{l}\text { Rendimento médio de } \\
\text { produção, kg/ha }\end{array}$ & 1.395 & 8.111 & 955 & -440 & 8.353 & +242 \\
\hline Valor de produção, mil reais & 280.927 & 231.506 & 131.284 & -149.643 & 497.537 & +266.031 \\
\hline
\end{tabular}

Fonte: PAM: Produção Agrícola Municipal: tabelas especiais do IBGE. Elaboração da autora.

\section{Considerações finais}

Da caracterização do perfil produtivo de agroindústrias, procuramos defini-las usando a denominação dos autores Schneider et al. (2014, p.114) como pluriatividades para-agrícolas, que se referem às atividades de " transformação, beneficiamento ou processamento artesanal, tradicionalmente para o consumo, que passam a ganhar escala industrial - pequena ou média, - e serem orientadas para a venda no mercado". Esta denominação, segundo os autores, se refere à produção de derivados de produtos de origem vegetal ou animal, processados em pequenas escalas, preferencialmente de matérias primas do próprio estabelecimento, e "no interior da propriedade mediante agregação de valor, surgindo como uma alternativa de emprego, de ocupação e renda para as famílias de pequenos agricultores”.

Quanto às políticas públicas, observa-se que o governo do estado está a acompanhar e adequar as suas estratégias às estratégias do governo Federal, nas ações do programa de agroindústrias de produção de agricultores familiares. Mas, deve ter em conta que, com cada novidade fiscal introduzida nos procedimentos legais, surgem novas dificuldades para os agricultores familiares em relação à elaboração de projetos, à infraestrutura física do estabelecimento e a docu-

8. Para elaboração de tabela 15 foi consultada a tabela especial 5457: Área plantada ou destinada à colheita, quantidade produzida, rendimento médio e valor de produção, disponibilizada no Sistema de recuperação automática - SIDRA do Instituto Brasileiro de Geografia e Estatística, IBGE: Produção Agrícola Municipal - PAM. 
mentos necessários para a sua construção ou reforma. A atualização de informação perante os agricultores, às vezes, não acontece tão rapidamente como as mudanças nos documentos oficiais e por isso, surgem estas e outras dificuldades que são enfrentadas por muitos produtores que não têm possibilidade de acompanhamento de formação destinada à sua atualização. Mesmo depois de ter os seus projetos aprovados e financiados, devido a não ter atualização, principalmente aquela relacionada à fiscalização sanitária e ambiental, a maioria deles nem começa a funcionar ou termina as suas atividades logo no início de existência. Como exemplo disso, pode ser citado o Edital de Chamada Pública nº. 008/2016, aberto pela Secretaria de Estado de Agricultura Familiar (SAF) que visa "o chamamento público para a seleção e apoio financeiro de projetos de revitalização de agroindústrias familiares instaladas com o financiamento concedido pelo governo estadual através do NEPE$^{9}$, SEDAGRO $^{10}$, SEDES $^{11}$, GISP ${ }^{12}$ ". No Edital, menciona-se que a justificativa do certame se baseia "na inoperância de 502 agroindústrias familiares implantadas pelas associações com o financiamento concedido pelo governo do Estado, das quais a maioria nem chegou a funcionar ou paralisou as atividades pouco tempo depois da implantação" (EDITAL nº. 008/2016).

Prezotto (2010), ao analisar as dificuldades das agroindústrias na região Sul do país, aponta em algumas dificuldades que as unidades familiares estão a enfrentar, entre as quais, a falta de registro ou pagamento de inscrição e anuidade, bem como, as exigências dos Conselhos Regionais de Química (CRQ) ou Conselhos de Medicina Veterinária (CRMV) de contratar os técnicos para atuarem junto das agroindústrias de alimentos e bebidas, o que envolve os custos adicionais. Para muitos produtores, as despesas com estes serviços por vezes são muito maiores do que os próprios investimentos realizados no início de atividade ou, excedem os rendimentos anuais, impedindo que as agroindústrias se mantenham em funcionamento. Por isso, muitas unidades com a capacidade mínima de produção não têm a possibilidade de pagar e ser acompanhadas de assistência técnica permanente e com ênfase pedagógica por parte de profissionais, que além de técnicos de extensão rural, são obrigadas a contratar os serviços de engenheiros agrônomos, médicos veterinários e profissionais de análises químicas, segundo exige a legislação brasileira. Este fator revela-se importante no planejamento de apoios e estímulos institucionais, para que os estabelecimentos agroindustriais familiares de pequeno porte e artesanais tornem-se viáveis e os projetos implementados tenham o menor índice de inoperância e maior retorno financeiro.

Em relação às agroindústrias rurais no modo geral, os dados do Censo Agropecuá-

9. NEPE - O Núcleo de Programas Especiais, órgão vinculado à Secretaria de Estado de Desenvolvimento Agrário e Agricultura Familiar.

10. SEDAGRO - Secretaria de Estado de Desenvolvimento Agrário e Agricultura Familiar.

11. SEDES - Secretaria Estadual de Desenvolvimento Social.

12. GISP - Gerência de Inclusão Sócioprodutiva, órgão vinculado a SEDES. 
rio de 2006 demonstraram que, no estado de Maranhão, a agricultura familiar foi responsável pela maior parcela de valores agregados à produção associados à transformação de alimentos, mesmo que esses valores não tenham sido muito expressivos nos índices de venda. Este fator viabiliza a função e o papel dos estabelecimentos familiares neste tipo de produção agroalimentar, como também foi revelado em pesquisas nas outras regiões (WESZ JUNIOR, 2009; BASTIAN et al., 2014; WAQUIL et al., 2014).

0 conhecimento de problemas enfrentados pelas unidades produtivas agroindustriais ajudou-nos a compreender melhor os resultados da pesquisa mais detalhados que seguem. Assim, os resultados relativos às quantidades de produtos destinadas à venda demonstraram que a maioria das famílias rurais do estado está envolvida em atividades econômicas voltadas principalmente à subsistência. Este fato significa que poucos agricultores conseguem desenvolver as atividades que permitem agregar valor aos produtos que eles produzem nos seus estabelecimentos. Observou-se também que, em todos os produtos processados, os agricultores utilizavam a matéria prima do próprio estabelecimento, e as quantidades adquiridas de fora foram muito pequenas.

A diferença significativa entre os indicadores de quantidade de leite produzida e beneficiada no próprio estabelecimento significa que este produto é usado principalmente no consumo da própria família, e não é destinado à comercialização. Em relação do produto de leite pasteurizado destinado à venda, o estado está com menores índices, depois do estado do Piauí. Estes números revelam a situação precária das agroindústrias especializadas na produção de leite e produtos derivados de leite no estado. Concluiu-se que aqueles agricultores que conseguem vender o excedente dos seus produtos e obter uma renda complementar têm as maiores possibilidades de investir no melhoramento das suas agroindústrias, ao contrário daqueles que não têm os produtos para vender ou não conseguem o acesso aos mercados por causa de outros problemas, entre os quais, o não cumprimento das normas sanitárias e ambientais e outros, que já foram mencionados.

Deste modo, os agricultores encontramse perante uma situação que Amartya Sen (2003) chama "a relação de mão dupla". Por um lado, as condições insatisfatórias no processo produtivo em qualquer parte da cadeia produtiva não permitem a obtenção de melhores rendimentos. Inversamente, os rendimentos satisfatórios poderiam ajudar na inovação de algumas partes dessa cadeia, por exemplo, investir em sala de ordenha ou em máquinas de produção de queijo.

Os resultados demonstraram que as atividades realizadas nas agroindustriais rurais não exigem alto nível de tecnologias nem qualificação, tendo em conta que os produtos que foram beneficiados e vendidos sofreram pouca transformação, o que se revelou em todas as agroindústrias de produção de produtos de origem animal: caso de carne tratada, leite e pescado, o que revela baixo nível de industrialização e, consequentemente baixo nível do valor agregado aos produtos produzidos, que na maioria não foram destinados à comercialização.

Corroborando a perspectiva de Wilkinson (2003) sobre a globalização do sistema agroalimentar, Wesz Junior (2009) menciona que, nesse novo ambiente de concorrência, a agricultura familiar está impedida de participar nas cadeias tradicionais de com- 
modities e extrair a lucratividade, tendo em conta que não possui as condições básicas para isso, tais como, "insumos modernos (genéticos e químicos), grandes maquinários e inovações tecnológicas”.

\section{Referências bibliográficas}

ABRAMOVAY, Ricardo. Subsídios e multifuncionalidade na política agrícola europeia. Economia Rural. Vol. 40. N. 2: 235-264. 2002. Disponivel em: <https://issuu.com/ricardoabramovay/docs/ subsidios_multifuncional/1>. Acesso em 25 jun. 2016.

\section{ANJOS, F.S. Agricultura familiar em transfor- mação: os colonos-operários de Massaranduba (SC). Pelotas, UFPEL, 1995.}

ANJOS, F. S.; CALDAS, N. V. Multifuncionalidade, turismo rural e pluriatividade: interfaces de um debate inacabado. Revista Espaço de Diálogo e Desconexão. Araraquara. v. 5. n. 1. jul/dez. 2012. Disponivel em: < http://seer.fclar.unesp.br/ redd/article/viewFile/5335/4487> Acesso em: 23 mai. 2016.

BASTIAN, L.; WAQUIL, P.; AMIN, M.; GAZOLLA, M. Agroindústrias rurais familiares e não familiares: uma análise comparativa. Redes. Santa Cruz do Sul, v.19, nº. 3, p. 51-73. set./dez. 2014. Disponível em: < online.unisc.br/seer/index.php/ redes/article/download/2679/pdf.>. Acesso em: 21 set. 2016.

CARNEIRO, M. J. Camponeses, agricultores e pluriatividade. Rio de Janeiro. Contracapa. 1998.

CARNEIRO, M. J., MALUF, R. S. Para além da produção: multifuncionalidade e agricultura familiar. Rio de Janeiro: Mauad. 2003.

CARNEIRO, M. S. Terra, Trabalho e Poder: Conflitos e Lutas Sociais no Maranhão Contemporâneo. AnnaBlume Editora. São Paulo, SP. Brasil. 177p. 2013.

CHAYANOV, A. V. The theory of peasant economy. Translated from the Russian end German editions. Homewood, III: R. Irwin, [1920]. 1966.

DECRETO nº. 5.741/2006. Disponivel em: < http://www.planalto.gov.br/ccivil_03/_ato20042006/2006/decreto/D5741.htm>. Acesso em: 26 out. 2016.

FRANKLIN, S. H. The European peasants: the final phase. London: Routledge. 1969.

FULLER, A.M. From part-time farming to pluriactivity: a decade of change in rural Europe. Journal of Rural Studies. v. 6. n. 4. p. 361-373. 1990. GRAZIANO DA SILVA, J. 0 novo mundo brasileiro. Campinas, UNICAMP. Instituto de Economia. 1999.

IBGE: Instituto Brasileiro de Geografia e Estatística: Censo Agropecuário de 2006. Brasil, Grandes Regiões e Unidades de Federação. 2009. Disponível em: < http://biblioteca.ibge.gov.br/visualizacao/periodicos/51/agro_2006.pdf $>$. Acesso em: 15 set. 2015.

IMIRANTE.COM: Lei das Agroindústrias é regulamentada pelo Estado. 2014. Disponivel em: < http://imirante.com/maranhao/noticias/2014/10/24/governo-do-estado-regulamenta-lei-das-agroindustrias.shtml>. Acesso em: 20 nov. 2016.

IMESC: Instituto maranhense de estudos socioeconômico e cartográfico. 2015. Disponível em: $<$ http://imesc.ma.gov.br/portal/Home>. Acesso em: 24 mai. 2015.

LEI $n^{\circ}$. 11.326, de 24 de julho de 2006. Disponível em: < http://www.planalto.gov.br/ccivil_03/_ ato2004-2006/2006/lei/111326.htm>. Acesso em: 15 mai. 2016.

LIMA, J.R.F.de. Efeitos de pluriatividade e rendas não agrícolas sobre a pobreza e desigualdade rural na região Nordeste. Tese (Doutorado em Economia Aplicada). Universidade Federal de Viçosa. Minas Gerais. 2008. 157p. Disponível em: < http://locus.ufv.br/bitstream/ handle/123456789/108/texto\%20completo.pdf? sequence $=1$ CtisAllowed=y $>$. Acesso em: $2 \mathrm{dez}$. 2016. 
KAUTSKY, K. La cuestión agraria. Estudo de las tendencias de la agricultura moderna y de la política agraria de la socialdemocracia. (Tradução de alemão Ciro Bayo). Problema Agrário: Marxists Internet Archive [1903] 2015. 502p Disponível em: <https://www.marxists.org/espanol/kautsky/1899/kautsky-la-cuestion-agraria.pdf $>$. Acesso em: 12 set. 2018.

MALUF, R. S. A expansão do capitalismo no campo: o arroz no Maranhão. Dissertação (Mestrado em História). Universidade Estadual de Campinas. Campinas. São Paulo - SP. 1977. 132p. Disponível em: <www.bibliotecadigital.unicamp.br $>$. Acesso em: 15 jul. 2016.

MARANHÃO: Agência Estadual de defesa agropecuária. Manual de orientação para registro da agroindústria familiar, pequeno porte e artesanal. São Luís. 2016. 54p. Disponível em: < http:// www.aged.ma.gov.br/files/2016/08/MANUAL-AGROINDUSTRIA-FAMILIAR-01-08.pdf > . Acesso em: 25 nov. 2016.

MIOR, L.C. Agricultores familiares, agroindústrias e redes de desenvolvimento rural. Chapecó: Agros. 2005. 338p.

NASCIMENTO, C. A pluriatividade das famílias rurais no Nordeste e no Sul do Brasil: pobreza rural e políticas públicas. Economia e Sociedade. Campinas. v. 18. n. 2(36). p. 317-348. 2009. Disponivel em: < http://www.scielo.br/pdf/ecos/ v18n2/a04v18n2.pdf>. Acesso em: 16 nov. 2016.

PLOEG, J.D.V.; VENTURA, F.; MILONE, P. Research for Agri Committee: Farm Structural change in Western Europe and the CAP, p.778. In: MASSOT, A. (Org.). Research for Agri Committee-Structural Change in EU-Farming: How CAN the CAP support a $21^{\text {st }}$ Century European model of Agriculture? Workshop-Studies. 2016. Disponivel em: < http://www.europarl. europa.eu/RegData/etudes/STUD/2016/573428/ IPOL_STU(2016)573428_EN.pdf>. Acesso em: 23 set. 2017.

POLANYI, K. El sistema económico como proceso institucinalizado. Antropologia y economía. CIESAS-UAM-UIA, p. 155-178. 1976. Disponível em:
$<$ http://ciesas.edu.mx/publicaciones/clasicos/articulos/Polanyi/pdf.>. Acesso em: 17 ago. 2016.

PREZOTTO, L.L. Programa de agroindustrialização da agricultura familiar 2007-2010. Material técnico sobre a atuação dos conselhos de classe nas agroindústrias da agricultura familiar. Brasília. 2010. Disponivel em: <http://www.mda.gov.br>. Acesso em: 12 set. 2016.

PREZOTTO, L. L. Uma concepção de agroindústria rural de pequeno porte. Revista de Ciências Humanas, Florianópolis, n. 31, p. 133-153, jan. 2002. Disponivel em: <https://periodicos.ufsc.br/ index.php/revistacfh/article/view/25195/22152>. Acesso em: 28 nov. 2016.

SCHNEIDER, S. Agricultura familiar e pluriatividade. Porto Alegre. Tese (Doutorado em Sociologia). Programa de Pós-graduação em Sociologia. Instituto de Filosofia e Ciências Humanas, UFRGS. 1999.

SCHNEIDER, S. Teoria social, agricultura familiar e pluriatividade. Revista Brasileira de Ciências Sociais. São Paulo: v. 18. n. 51. p. 98-121. 2003. Disponível em: <http://www.ufrgs.br/pgdr/arquivos/389.pdf>. Acesso em: 25 set. 2015.

SCHNEIDER, S. A pluriatividade na Agricultura Familiar. Porto Alegre. Editora UFRGS. 2003a.

SCHNEIDER, S., et al. Pluriatividade e plurirendimentos nos estabelecimentos agropecuários do Brasil e das regiões Sul e Nordeste. In: SCHNEIDER, S.; FERREIRA, B.; ALVES, F. (Orgs.). Aspectos multidimensionais da agricultura Brasileira: diferentes visões do Censo Agropecuário 2006. Instituto de Pesquisa Econômica Aplicada-IPEA. Brasília. p. 107-134. 2014. Disponível em: < http://www.ipea.gov.br/portal/images/stories/ PDFs/livros/livros/livro_aspectos_multidimensionais.pdf>. Acesso em: 16 nov. 2016.

SCHNEIDER, S.; FERREIRA, B.; ALVES, F. (Orgs.). Aspectos multidimensionais da agricultura Brasileira: diferentes visões do Censo Agropecuário 2006. Instituto de Pesquisa Econômica Aplicada-IPEA. Brasília. 2014. Disponivel em: < http:// www.ipea.gov.br/portal/images/stories/PDFs/ 
livros/livros/livro_aspectos_multidimensionais. pdf>. Acesso em: 16 nov. 2016.

SEDES: Secretaria de Estado de Desenvolvimento Social. 2014. Disponivel em: <http://www.sedes. ma.gov.br/2014/07/16/maranhao-e-2o-no-nordeste-em-aplicacao-do-pronaf-para-a-agricultura-familiar>. Acesso em: 21 de mai. 2016.

SEN, A. 0 desenvolvimento como Liberdade. (Tradução Joaquim Coelho Rosa). Gradiva. 2003. $365 p$.

\section{SECRETARIA DE ESTADO DA AGRICULTURA}

FAMILIAR: EDITAL, no. 008/2016. Disponivel em: <http://www.saf.ma.gov.br/files/2016/04/8-Edital-de-Chamada-Publica-nº-008-AGROINDUSTRIA.pdf.>. Acesso em: 23 out. 2016.

SIDRA/IBGE: Sistema IBGE de recuperação automática. Censo Agropecuário de 2006. Disponível em: <https://sidra.ibge.gov.br/pesquisa/censo-agropecuario/censo-agropecuario-2006/segunda-apuracao\#agricultura-familiar>. Acesso em: 09 dez. 2017.

SILVA, S. A Agricultura Familiar e suas múltiplas interações com o território: uma análise de suas características multifuncionais e pluriativas. Texto para discussão. Instituto de Pesquisa Econômica Aplicada - IPEA. Brasília. 2015. Disponível em: <http://www.repositorio.ipea.gov.br/bitstream/11058/4162/1/td_2076.pdf. $>$. Acesso em: 15 nov. 2016.

SILVA, L.A.G.C. Agroindustrialização na agricultura familiar. Nota técnica. Câmara dos Deputados. Brasília. 2012. Disponível em: < http://www2.camara.leg.br/documentos-e-pesquisa/publicacoes/estnottec/areas-da-conle/ tema2/2012_16756.pdf>. Acesso em: 2 dez. 2016.

SOUZA, S.; LIMA, J.; SILVA, A. A evolução de pobreza nas famílias rurais na região Nordeste: 2003-2009. Teoria e evidência econômica. Ano 17, n. 36, p. 80-97. 2011. Disponível em: < http://seer.upf.br/index.php/rtee/article/viewFile/4243/2732>. Acesso em: 16 nov. 2016.

STC: Secretaria de Transparência e Controle. Lei Estadual $n^{\circ}$. 10.086, de 20 de maio de 2014. Dis- ponivel em: < http://www.stc.ma.gov.br/legisladocumento/?id=3720>. Acesso em: 20 nov. 2016.

WAQUIL, P.D. et al. 0 perfil da agroindústria rural no Brasil: uma análise com base nos dados do Censo Agropecuário 2006. In: SCHNEIDER, S.; FERREIRA, B.; ALVES, F. (Orgs.). Aspectos multidimensionais da agricultura Brasileira: diferentes visões do Censo Agropecuário 2006. Instituto de Pesquisa Econômica Aplicada-IPEA. Brasília. 2014. Disponível em: < http://www.ipea. gov.br/portal/images/stories/PDFs/livros/livros/ livro_aspectos_multidimensionais.pdf >. Acesso em: 16 nov. 2016.

WILKINSON, John. Agricultura familiar ante o novo padrão de competitividade do sistema agroalimentar na América Latina. Estudos Sociedade e Agricultura. Rio de Janeiro. no. 21. p. 6287. 2003. Disponível em:<.http://r1.ufrrj.br/esa/ V2/ojs/index.php/esa/article/viewFile/239/235> . Acesso em: 24 ago. 2017.

WESZ JÚNIOR, V.J. Agroindústria familiar: um mecanismo de estímulo à especialização das atividades na propriedade rural? Mundo Agrário, vol. 9, nº 18, La Plata, ene./jun. 2009. Disponivel em: <http://www.scielo.org.ar/scielo.php?script=sci_arttextCtpid=S1515-59942009000100002>. Acesso em: 25 nov. 2016. 
RESUMO

No artigo, propõe-se a caracterização de algumas agroindústrias rurais no estado do Maranhão, baseada nos dados do Censo Agropecuário de 2006. Como ponto de partida para a pesquisa, serviu o fato de que as agroindústrias de produtos agropecuários se destacam como principais atividades entre as ocupações pluriativas dos agricultores familiares do estado. A escolha de agroindústrias para análise é fundamentada pela sua importância no sistema de produção agroalimentar e pela maior participação da agricultura familiar nos valores agregados dos produtos processados. $\mathrm{Na}$ literatura pesquisada, defende-se a visão de que, no contexto de pluriatividade a diversificação das atividades, que ocorre por meio de criação de agroindústrias familiares, de pequeno porte e artesanais, pode ser apontada como uma alternativa econômica para que a agricultura familiar possa permanecer e desenvolver-se em paralelo com as agroindústrias de grande escala e, assim, contribuir para a construção de um novo modelo de desenvolvimento dentro do qual o rural seja pensado como um todo, e não mais apenas ligado à produção agrícola.

\section{PALAVRAS-CHAVE}

Pluriatividade. Agroindústrias. Agricultura Familiar. Censo Agropecuário 2006.

\section{ABSTRACT}

The article proposes the characterization of some rural agroindustries in the state of Maranhão based on data from the 2006 Agricultural Census. As a starting point for the research served the fact that agroindustries of agricultural products stand out as the main activities among the pluriactive occupations of the family farmers of the State. The choice of agroindustries for analysis is based on their importance in the agro-food production system and the greater participation of family agriculture in the aggregated values of processed products. In the researched literature, it is defended the view that, in the context of pluriactivity, the diversification of activities that occurs through the creation of small family and artisanal agroindustries, can be pointed out as an economic alternative so that family agriculture can remain and develop in parallel to the large-scale production and thus contribute to the construction of a new model of development in which the rural is thought as a whole and no longer only linked to agricultural production.

\section{KEYWORDS}

Pluriactivity. Agroindustries. Family Farming. 2006 Agricultural Census.

Recebido em: 11/12/2016

Aprovado em: 19/12/2018 